of the Society was in a great measure Scottish, and Sir D. Brewster, Mr. Robison and yourself have always been looked upon as its founders. . . ." A copy of this letter he sent to Sir Roderick Murchison, saying: "My dear friend, you are a Scotsman, and though a deserter, you should not quite desert what is due to your country. Only look back and remember what Scotland did for the Association. . . ." Forbes had his way. The meeting was successful and he had the pleasure of entertaining Whewell, Peacock and Vernon Harcourt, of the last-named of whom he wrote, "I learn every year to look with more admiration and affection on that remarkable man". Brisbane, whose name is perpetuated by the capital of Queensland, it may be added, died at his birthplace, Brisbane House, Largs, at the age of eighty-six, and Brewster died at the same age at Allerly, Melrose, but Forbes died at Clifton at the age of fifty-nine. Forbes's grave is in the Dean Cemetery, Edinburgh, and that of Brewster in the grounds of Melrose Abbey.

\section{RESEARCH IN OCEANOGRAPHY}

7 HE sea, covering as its does three-quarters of the surface of the earth, presents unnumbered problems to whet intellectual curiosity and adventure, while economic and utilitarian motives for its scientific study are also pressing. Marine biology has always been actively pursued; in earlier days largely by amateurs and latterly by professionals at a number of well-equipped and well-staffed marine laboratories. Since zoology cannot be studied without regard for marine species, the universities of Britain have always fostered and, no doubt, always will foster, marine research on a considerable scale. Fewer botanists have found such interest in the plants of the sea. Economic stimulus has stimulated investigation of the shore seaweeds, and a research association now exists for this purpose alone.

Fundamental marine zoology has found its economic counterpart in fisheries research undertaken by the Laboratories at Lowestoft and Aberdeen, both full of vigour and ideas. These laboratories have had to study not only fish but also the food of fish and the waters which nourish and transport it. Study of the invertebrate fauna of the sea and the sea bed is in a healthy state; so is the physical and cheraical study of the waters which fill the shallow seas frequented by fishing vessels. A re-deployment of effort is in progress; more hands would provide quicker results, but, in relation to the scientific man-power of the country, the staff available, especially in quality, is reasonable.

The Antarctic has become one of the best known of the major oceans by the tireless work of the Discovery Committee and its ships and staff, the contributions of which both to marine biology and to physical oceanography have been great. None the less, the motive for all their work has been economic - to provide a scientific foundation for the whaling industry. There have been huge fields of physical investigation which were neither proper for their study nor could they be undertaken with their limited staff. The entire expenses of the Discovery Committee have been met by the Government of the Falkland Islands from a cess levied on all whales processed in the Falklands or their territorial waters. Great Britain's contribution has been a negative one-revenue derived by taxation of the staff who live here.
Investigations to secure safer navigation have always been and remain the concern of the Hydrographer of the Navy. There was a time when the British Hydrographic Office unaided charted the seas of all the world. To-day the Admiralty's fleet of survey ships forms only a part of the survey fleet of the world, but the quality of its work ranks as high as ever. Tidal investigations flourish both at the Admiralty and at the Liverpool Tidal Institute, the annual report* of which has just been published.

Theoretical investigations of much importance, especially in hydrodynamics, have been made by a few gifted free-lances in the universities, but physical oceanography has been ill organized. Apart from nuclear physics, oceanography is probably the most expensive of all scientific techniques, so that there has been little opportunity for experimental physical investigation or for deep-sea research. Submarine geology and geophysics are in the hands of a few men at a single university, who have had to borrow ships when needed as best they could.

At a meeting of the Scientific Advisory Committee of the War Cabinet in January 1944, Vice-Admiral Sir John Edgell, then Hydrographer of the Navy, expressed the view that Great Britain, in its contribution to research in oceanography, had fallen seriously behind other countries, and suggested that a British oceanographical institute should be set up without delay. Inquiry showed that there was a considerable body of opinion in favour of concentrating the efforts upon physical studies, which had been neglected as compared with marine biological research. However, the Scientific Advisory Committee considered that the work of the proposed institute should embrace both physical and biological oceanography. In July 1946, the Colonial Office raised the question of the future of the Discovery Investigations. This matter was considered by various government departments interested and by the Advisory Council on Scientific Policy in conjunction with the earlier proposals, and as a result the National Oceanographic Council and the National Institute of Oceanography came into being (see Nature, March 17, p. 415). The steps leading to the formation of the Institute are indicated in its first annual report $\uparrow$.

The National Institute, with Dr. G. E. R. Deacon as first director, has taken over the Oceanographic Group of the Royal Naval Scientific Service at the Admiralty Research Laboratory at Teddington, and also the Discovery Investigations, which had ceased to be the responsibility of the Falkland Island Dependencies on March 31, 1949; the Institute is also gradually taking over part of the work of the Oceanographical Branch of the Hydrographer of the Navy. The R.R.S. Discovery II and R.R.S. Williarn Scoresby were purchased by the Admiralty from the Government of the Falkland Islands Dependencies and presented to the Institute. The shore work of the Institute remains dispersed among five establishments in the London area and one in Cornwall. The very desirable concentration under the director in one place remains to be achieved.

Both the research vessels were under requisition during the War, and their equipment in store was destroyed by enemy action. Both ships have needed extensive refitting and re-equipment before resuming * Liverpool Observatory and Tidal Institute: Annual Report,
1950. Pp. 16.

$\dagger$ Annual Report of the National Institute of Oceanography 1949 50. Pp. 48. (Cambridge: At the University Press, 1951.) 58. net. 
the Discovery Committee's programme in the southern hemisphere. R.R.S. William Scoresby was first to sea in January 1950 and proceeded to survey the Benguela Current off the coast of south-west Africa. It can be seen already that much information of first importance on the physics and chemistry of the current and on its faunistic content was obtained, and that the resources of the Institute will be strained to evaluate and publish the results in reasonable time. This ship also carried out fishing experiments in South African waters, some whale-marking and a considerable amount of work on the Agulhas Current before returning to England last autumn.

The larger R.R.S. Discovery II put to sea in May 1950 and proceeded to the southern hemisphere to undertake investigations on the lines of those between the Wars, but at seasons and in parts of Antarctic and Australasian waters previously least investigated. There was also a considerable number of other programmes for investigation. She is still at sea, but it is clear already that she will return prepared to add much to knowledge. The sea programme of the Discovery Committee will then have been completed. The working up of the vast faunistic collections must continue for many years. Similarly, the complete evaluation of the chemical and physical observations by the two ships at about four thousand stations during twenty years will require much effort.

The work on waves, swell, microseisms and currents initiated at the Admiralty Research Laboratory is being continued by the Institute. Although the main object of the wave research is to obtain quantitative information about the factors which influence the generation, propagation and decay of waves, such as will allow the wave conditions at any place to be predicted from wind charts and a knowledge of the local hydrography, the techniques which have been developed have immediate applications in places where meteorological information is not available. Such a possibility is being considered for Mauritius, where there is need of warning of the approach of a cyclone or heavy swell over the off-lying shoals used by local fishermen.

Modern oceanography demands larger ships, manned by officers and crew well versed in their speciulized duties. The experience of the Discovery Committee, shared by the marine laboratories, is that it takes time to select and train such staffs and that it is a tragedy if key personnel have to be dispersed when a ship has to be laid up. But the larger ships liave the capacity of collecting at a great rate. Even under the most favourable conditions, it will take a man ten weeks to work up observations which he can collect in one. Yet it would seem that the two vessels will have to be kept at sea and their collections and results appreciated, and the parallel laboratory investigations continued, by a staff of no more than sixteen scientific and six experimental officers. If these valuable, but expensive, ships are to be put to best use, a very considerable recruitment of staff would seem necessary.

In most fields of marine study the days of collecting for the sake of collecting are ended. The museums are stuffed with millions of specimens and station lists with hundreds of thousands of observations, woefully inadequate to give a true picture of the ocean it is true, but beyond the capacity of the systematists and physical oceanographers of Great Britain or, for that matter, of the world to work up. Support is more readily obtained for dispatching a spectacular expedition than for the quiet working up of the results afterwards or for their publication. An adequate theoretical background and due selection of problems for work at sea is now possible and can lead to great economy. There is no doubt but that the National Institute of Oceanography under its present director will seek to achieve this.

Cost of publication everywhere presents a grave problem often met by the compression of papers to the point of incomprehensibility. In chemistry the high reproducibility of experimental results and standardization of techniques may make possible compression intelligible to the initiated, but not so in oceanography. In the sea the same situation never repeats itself and, the cost of getting observations being what it is, each one has to carry all the interpretation it can bear. The cost of the many necessary illustrations is now very high, and it seems less easy to get the relatively small funds for publication than for the prosecution of the actual research. May one hope that the Institute will be able to maintain the high standard of presentation of Discovery Reports?

Great Britain should be grateful that the creation of the National Institute of Oceanography has been courageously tackled and that investigations are proceeding on a wide front. It should get good value for the annual grant of $£ 115,000$ which departments of the home Government and certain Dominion Governments are providing. L. H. N. CoOPER

\section{BRITISH INSTRUMENT INDUSTRIES EXHIBITION}

THE Exhibition of the British Instrument Industries, which took place during July 4-14, in the National Hall, Olympia, London, owed its inception to a suggestion made by the Department of Scientific and Industrial Research. Some two years ago, the Department put forward the suggestion that it might be helpful and instructive to industry if an exhibition could be staged at which equipment, covering the entire range of industrial instrumentation, could be displayed and its use demonstrated. This suggestion was put before a meeting of interested trade associations who, while accepting the Department's recommendation, felt that the scope of the Exhibition should be extended to include the products of the whole field of British instrument manufacture, covering every variety of the use of instruments. This wider conception provided the background of the Exhibition which has recently concluded, and the successful achievement of these aims has been an event of unusual sig-. nificance in the long history of instrument-making in Great Britain.

There has been a tendency for instrument interests to become sectionalized, according to the broad uses of various classes of instruments, and the five participating trade associations (British Electrical and Allied Manufacturers' Association; British Industrial Measuring and Control Apparatus Manufacturers' Association ; British Lampblown Scientific Glassware Manufacturers' Association; Drawing Office Material Manufacturers' and Dealers' Association; and the Scientific Instrument Manufacturers Association of Great Britain, Ltd.) have emerged as representing groups of manufacturers of instruments having certain specific fields of use, although the last-named association, S.I.M.A., covers instrument 